\title{
Indicators of reliability and efficiency of construction production processes
}

\author{
Konstantin Losev ${ }^{1, *}$ and Vitaly Chulkov ${ }^{2}$ \\ ${ }^{1}$ Moscow State University of Civil Engineering, 129337, 26, Yaroslavskoe Shosse, Moscow, Russia
}

\begin{abstract}
The study contributes to interrelation of innovative and traditional indicators of reliability and efficiency of construction production processes. The object of the article is organizational and technological potential of the processes of construction production and two of its research directions: 1) an infographic modeling of the parameters for the creation and functioning of systems of organizational design and management in construction; 2) a concept of organizational and technological potential (of the efficiency of the construction process). An important aspect of the sufficiency of the potential of the reliability of construction production is the use of a balanced system of interrelated indicators. The subjects of research in the article are innovative and traditional indicators of reliability and efficiency of construction production processes. The task of the study was to analyze interrelation of innovative and traditional indicators and determine groups of interrelated indicators and determine the average values of the readiness indicator value ranges. An infographic modeling method and a predominantly deterministic inverse multi-stage dynamic perspective factor analysis have been used in the study. The four groups of interrelated indicators have been determined for a construction company performance evaluation: financial, client, internal business processes, training and development. The average values of the readiness indicator value ranges have been obtained by the average statistical values of mean time between failures: $0.86-0.92$ for technical equipment and SMIT; $0.80-0.85$ for material resources and components; $0.78-0.83$ for labor resources.
\end{abstract}

\section{Introduction}

The analysis of the problems of reliability (as a functional evaluation indicator of quality) and the efficiency of construction production are devoted to the publication of numerous domestic and foreign researchers (Yu.B. Monfred, B.V. Prykin [1], A.A. Gusakov [2], T.N. Tsai, P.G. Grabovyy, V.A. Bolshakov et al. [3], L.G. Dikman [4], V.A. Zarenkov [5], V.M. Serov, N.A. Nesterova et al. [6], P.P. Oleinik [7], Z.M. Hadonov [8], A.V. Ginzburg [9], O.G. Prudnikova [10], R.K. Ghazaryan, V.O. Chulkov et al. [11, 25, 26 et al.], V.N. Kabanov et al. [12, 18 et al.], A.A. Lapidus, A.N. Makarov, et al. [13, 16 et al.], A.A. Morozenko et al. [14], V.Z. Velichkin [15], N.A. Shulzhenko et al. [17], Paulson, Boud C., Jr.Barrie,

\footnotetext{
*Corresponding author: LossevKY@mgsu.ru
} 
Donald S. [19], Lu M., Li H. [20], Nepal M.P., Park M. [21], El-Diraby T.E., O'Connor JT [22], Deborah A., Abowitz T., Michael T. [23], Qing Fan, Hongqin Fan [24] and others).

Indicators of the potential reliability and effectiveness of the investment construction project implementation, the ICP (prognostic indicators of the planned quality of the ICP implementation) and the actually achieved reliability and efficiency of the construction or reconstruction of the construction object (the actual indicators of the achieved quality of the ICP implementation) are considered as two different but interrelated groups of tools for assessing reliability and construction production quality.

Construction science traditionally considers the possibility of ensuring the organizational and technological reliability (OTR) of the processes of construction production at the expense of organizational, technological and managerial decisions. OTR is the basis of a recognized scientific and practical activity in construction. One of the research directions and evaluation of OTR is infographic modeling ("infographic", VO Chulkov [25, 26, etc.]) of the parameters for the creation and functioning of systems of organizational design and management in construction. A significant contribution to the study of problems of OTR was made by the scientific school BV Prykin, which studies the problem of the sufficiency of the potential of a construction organization in the operation of real construction processes [27]. An important aspect of the sufficiency of the potential of the OTR of construction production is the use of a balanced system of interrelated indicators [10 and others]. A number of researchers consider preservation the integrity of the object being assessed as a prerequisite for ensuring the OTR provision of an investment construction project implementation. [28], Fig. 1.

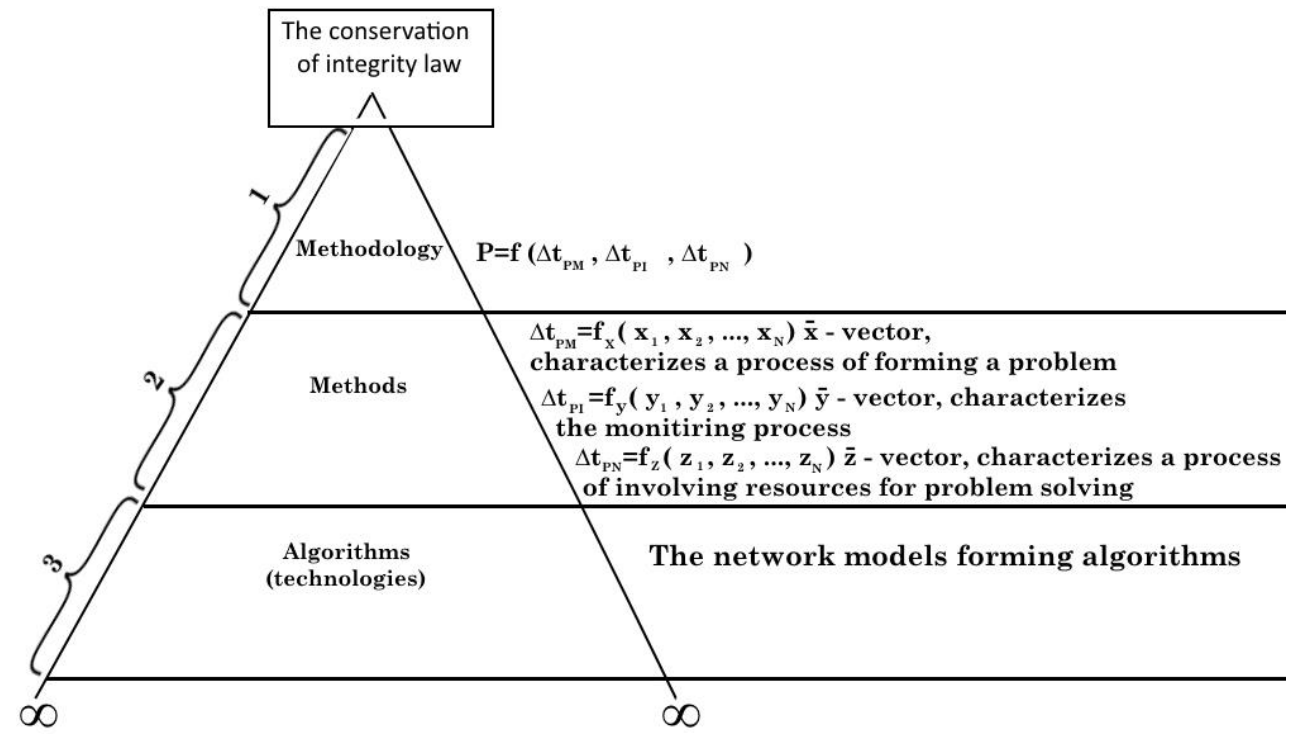

Fig. 1. The Model of the law of assessment object integrity preservation (according to VG Burlov [28]).

OTR is increased by:

- reducing the complexity of the system and reducing the number of influencing parameters subject to failure;

- designing the maintenance of the OTR of the system during its operation, reducing the labor costs of the construction industry, reducing the number of its units and the hierarchy of the organizational structure of production.

The basis of the OTR research methodology is:

- probabilistic-statistical approach; 
- mathematical modeling;

- comprehensive assessment of construction processes in the adopted organizational and technological solutions;

- reliable forecast of possible failures.

The concept of organizational and technological potential (OTP) $[13,16,27$ etc.] of the efficiency of the construction process has been introduced to the development of an investment construction project as an innovation. A systematic approach to the study of ONP requires a preliminary study of the OTR of individual elements and operations of the construction industry. Innovative and traditional indicators of reliability and efficiency of construction processes are interrelated. This relationship helps to improve the assessment of the quality of functioning of the construction industry in the process of implementing the investment construction process. When comparing OTP options, the operation and construction indicators are considered as a criteria of economic efficiency.

For each of these two aggregates, the main ones are distinguished (the volume of capital investments, the cost of construction products, the cost per unit of production) and additional indicators. There are common (absolute) and comparative (relative) efficiency. Overall effectiveness assesses the results at the macro and micro levels of the building industry for a specific period of time. Comparative efficiency is used to substantiate organizational and technological solutions when choosing the best alternative option. To increase the efficiency of construction, it is necessary to improve the methods of ensuring its organizational and technological reliability.

The main multidimensional methods for study sets of innovative and traditional indicators of the construction processes reliability and efficiency, as well as their interrelationships, are factor and correlation-regression analysis. These are well-known methods for studying the relationship between the parameters of variables in their individual sets or between such sets. The researcher examines the structure of covariance or correlation matrices and determines the similarity and difference of the parameter values, thereby ensuring the reliability of the results of scientific research. It detects (measures) the current values of the parameters selected by it for the full analysis, and determines the degree of influence of each factor on the resulting actual value of the parameter.

There are ten types of factor analysis of the construction processes reliability and efficiency. The most researchers commonly use deterministic analysis, which is quite simple and allows you to identify the logic of the impact of the main factors on the basis of quantitative values of process parameters. As a result, they reveal the factors that need to be influenced in order to increase the efficiency of the investment construction project. Stochastic analysis allows us to investigate factors that are related to actual performance indicators of an investment construction project is probabilistic (correlation). This analysis is used in cases where it is not possible to detect direct relationships and there is a need to investigate existing indirect relationships. A direct relationship with a change in argument changes the value of a particular factor. Indirect communication implies a change in several indicators with a change in the argument, and in varying degrees for each of them. With direct (deductive) factor analysis, research is conducted from the general to the particular, and with the reverse (inductive) analysis - from the particular to the general. Single-stage factor analysis examines the factors of one level of subordination without their detailed structuring. Multistep analysis involves the specification of factors located at different levels of the organizational hierarchy of the construction industry and the identification of inter-level relationships of such factors. Static analysis implies identifying the interrelationships of factors on a fixed date, and dynamic factor analysis examines cause-effect relationships in dynamics. The reasons for the changes in the interrelationships of factors in previous periods of time explore retro-factor analysis. Prospective changes in factors and modeling of the dynamics of such a change explores perspective factor analysis. 


\section{Methods}

The infographic modeling method is considered as the basis of systematic scientific study of a building production processes reliability and efficiency and relationships between its innovative and traditional indicators [29] (Fig. 2).

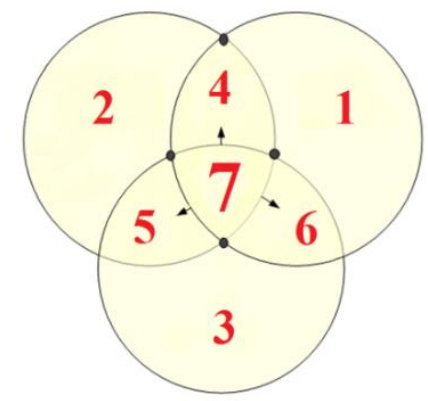

Fig. 2. The structure and relationship of the diversity in assessments reliability and efficiency in construction industry (VO Chulkov, 2017).

There are items in Figure 2: 1 - prognostic estimates of reliability and efficiency in the design of activities in the construction industry; 2 - assessments of the current values of reliability and efficiency in the process of monitoring the implementation of activities in the construction industry; 3 - actual assessments of the reliability and effectiveness of the results of completed activities in the construction industry; 4 - assessments of the reliability and efficiency of activities in the construction industry at the stages of its beginning and development; 5 - assessments of the reliability and efficiency of activities in the construction industry at the stages of its full implementation and completion; 6 - a comparative analysis of prognostic and actual assessments of the reliability and efficiency of activities in the construction industry; 7 - the field of assessment of the reliability and efficiency of activities in the construction industry as a whole, at all its successive stages.

In the study and application of the concept and criterion of the organizational and technological resource potential of the effectiveness of the construction process, we agree to distinguish between tangible and intangible aspects. The tangible aspect of such resource potential includes technical, financial, personnel and material components. The intangible aspect contains organizational, technological, managerial, temporal, human, information and communication, spatial, protective and image components.

The required level of the resource potential of the construction industry implies a following forecast:

- characteristics of the available resources of the construction company;

- dynamics of changes in the external environment of this organization;

- market situation at the moment and for the future;

- required quality characteristics of the processes of construction production and its results.

In the process of such a forecast, it is necessary to:

- perform an analysis of the existing resource potential of the construction organization, as a result, identify the permissible costs of improving this resource potential through its tangible and intangible components listed above;

- determine the reliable and rational need for the development of the resource potential of the construction organization and identify the reserves for increasing, reliability and stabilizing this potential. The reliability of the resource potential of a construction enterprise implies the property of the resources of this enterprise (people, technical means of mechanization and transportation, etc.) to ensure the fulfillment of functional properties and 
responsibilities while maintaining the values of planned and regulatory performance indicators within the specified limits corresponding to the intended modes of their use in the construction industry. [30]

\section{Results}

A predominantly deterministic inverse multi-stage dynamic perspective factor analysis, performed by the "absolute differences" method with the a linear regression of $y=a+b x$ result presentation is considered as a result visualization example (Fig. 3).

When studying of the quantitative values of the reliability of the construction and installation work (CIW), the reliability of individual operations and the means of mechanization and transportation (MMaT) functioning on these operations were determined at the beginning. Then, the reliability of the whole process of this type of work and the joint functioning of the MMaT aggregate were determined. In the specific conditions of the construction or refurbishment of a construction object, the reliability of the studied individual construction and installation operations CIW was different and depended on the occurrence of MMaT failures.

\section{The cost of an investment construction project, hundreds of thousands of} rubles

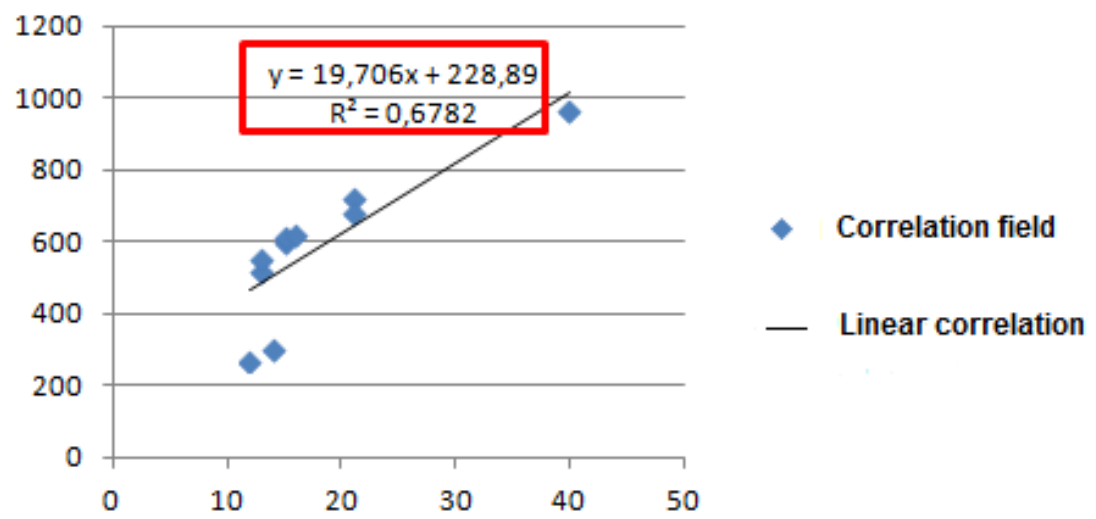

The cost of one square meter, thousand rubles

Fig. 3. The result of correlation and regression analysis (performed in Excel).

The reasons for MMaT failures were grouped into several aggregates: technical and organizational (MMaT malfunction; power supply, water supply and drainage networks malfunction; MMaT technical exploitation, etc.); organizational and technological (unforeseen work; incomplete delivery of products and materials; violation of delivery terms; failure of engineering communications and transport routes; untimely development of organizational and technological documentation, etc.); organizational and sociological (lack of workers with the required specialty and qualifications; failure to comply with production standards; non-appearance of workers for work without explaining the reasons, etc.).

The numerical values of MMaT separated and integrated reliability indicators have been determined, among which the readiness ratio should be considered the most generalizing as the ratio of MMaT uptime in full time over the observation period. The average values of the ranges of readiness factor values were obtained by the average values of mean time between failures: for technical equipment and SMIT: 0.86-0.92; for material resources and components: $0.80-0.85$; for labor resources: $0.78-0.83$. When determining the reliability of 
a certain type of a construction and installation work performing, it was necessary to take into account the combination of individual operations and processes, that is, the possibility of their simultaneous execution on different hooks.

The effectiveness of the study was considered for its four types: organizational (changing the functional responsibilities of employees, optimizing the organizational structure of the enterprise, reducing the number of employees, etc.); technological (introduction of new modern technologies, purchase of new equipment, increase in labor productivity, etc.); social (creation of conditions for creative work, improvement of the psychological climate in the team, reduction in staff turnover, etc.); environmental (safety of employees, environmental safety of processes and technologies of building production, etc.); legal (legality and stability of business processes, reduction of penalties, etc.).

\section{Summary}

Innovative and traditional indicators of construction processes reliability and efficiency are interrelated and it assesses the quality of construction at every stage of the construction investment process.

The Balanced Scorecard Complex (BSC) of separated and integrated reliability indicators considers the performance of a construction company upon four interrelated indicators: financial, client, internal business processes, training and development.

The average values of the readiness indicator value ranges have been obtained by the average statistical values of mean time between failures: 0.86-0.92 for technical equipment and SMIT; $0.80-0.85$ for material resources and components; $0.78-0.83$ for labor resources.

Within the BSC framework, the indicators target values which meet the strategic objectives of the construction company are determined. If an actual value of the indicator does not reach its target value, this shows the presence of a factor that hinders or delays the achievement of the investment project strategic goal. Along with this, the absence of a final integral indicator in the BSC, the indicator that would measure the implementation success of a construction company efficiency, as could be measured now by known Russian domestic criteria ("OTN" and "potentsial"), it makes the BSC an object for further refinement and improvement.

\section{References}

1. Yu.B. Monfred, B.V. Prykin, Organization, planning and management of construction industry enterprises, textbook for universities (Stroyizdat, Moscow, 1989)

2. A.A. Gusakov, Organizational and technological reliability of construction (SVRArgus, Moscow, 1994)

3. T.N. Tsay, P.G. Grabovy, V.A. Bolshakov, Organization of the construction industry, textbook for universities (DIA, Moscow, 1999)

4. L.G. Dikman, Organization of construction, Textbook (DIA, Moscow, 2006)

5. V.A. Zarenkov, Project Management, Tutorial (DIA, Moscow, 2006)

6. V. M. Serov, N.A. Nesterova, Organization and management in construction, A textbook (Akadem. Publ. Centre, Moscow,2008)

7. P.P. Oleynik, Organization of construction: Scientific publication (DIA, Moscow, 2010)

8. Z.M. Hadonov, Organization, planning and management of construction production, Textbook (DIA, Moscow, 2010)

9. A.V. Ginzburg, Vestnik MGSU 4, 251-255 (2010) 
10. O.G. Prudnikova, Assessment of the effectiveness of the construction enterprise on the basis of a balanced scorecard, The Ph.D thesises (Moscow, 2011)

11. R.K. Gazaryan, V.O. Chulkov, K.P. Graboviy, K.Yu. Kulakov, Vestnik MGSU 3, 218 222 (2012)

12. V.N. Kabanov, E.V. Mikhailova, Economics of Construction 4, 67-79 (2012)

13. V. Pukhkal, A. Mottaeva, Magazine of civil engineering 81(5), 202-211 (2018)

14. A.A. Morozenko, I.E. Voronkov, Industrial \& Civil Construction 12, 30-32 (2014)

15. V.Z. Velichkin, Engineering J. 7, 74-79 (2014)

16. A.A. Lapidus, A.N. Makarov, Industrial and civil construction 6, 66-71 (2016)

17. N.A. Shulzhenko, Yu.N. Pushilina, D.I. Chubarov, News of Tula State Uni. 7-2, 152157 (2016)

18. V.N. Kabanov, Science Forum Materials 931, 1249-1254 (2018)

19. C.B. Paulson, S.D. Jr. Barrie, Professional Construction Management (McGraw-Hill, 1992)

20. M. Lu, H. Li, J. of Construct. Eng. \& Mngt. 129-4, 412-420 (2003)

21. M.P. Nepal, M. Park, Engineer., Construct. \& Architect. Mngt 11(3), 199-210 (2004)

22. T.E. El-Diraby, J.T. O’Connor, J. of Prof. Issues in Engineer. Edu.\& Practice 130(2), 109-114 (2004)

23. D.A. Abowitz, T. Michael, J. of Construct. Engineer. \& Mngt. 136(1), 38-49 (2010)

24. Q. Fan, H. Fan, J. of Adv. Mngt. Science 3(3), 203-210 (2015)

25. V.O. Chulkov, Infographics: Course of lectures (MISI, Moscow,1991)

26. V.O. Chulkov, G.O. Chulkov, Infographics: A modular course of lectures (SVR-Argus, Moscow, 2006-2008)

27. B.V. Prykin, Technical and economic analysis of production, A textbook for universities (UNITI-DANA, Moscow, 2000)

28. V.G. Burlov, A.M. Grobitsky, A.M. Grobitskaya, Engineer. \& Construct. J. 3(63), 7791 (2016)

29. V.O. Chulkov, K.Yu. Losev, G.O. Chulkov, Science Forum Materials 931, 1233-1237 (2018)

30. V.O. Chulkov, K.Yu. Losev, G.O. Chulkov, IOP Conf. Series Materials: Earth and Environmental Scienc. 177, 012026 (2018) 